\title{
Evaluation model of art internal auxiliary teaching quality based on artificial intelligence under the influence of COVID-19
}

\author{
Luo Yuan ${ }^{\mathrm{a}, *}$, Zhao Xiaofei ${ }^{\mathrm{b}}$ and Qiu Yiyu ${ }^{\mathrm{c}, \mathrm{d}}$ \\ ${ }^{\mathrm{a}}$ Wuhan Institute of Design and Sciences, WuHan, HuBei, China \\ ${ }^{\mathrm{b}}$ Nankai University, Tianjin, China \\ ${ }^{\mathrm{c}}$ School of Mechanical Engineering, Yangtze University, Jingzhou, Hubei, China \\ ${ }^{\mathrm{d}}$ Siemens AG, Munich, Germany
}

\begin{abstract}
At present, the evaluation of normal teaching order and teaching quality has been seriously interfered by the impact of COVID-19. In order to ensure the quality of art classroom teaching, this article uses BP neural network technology to build a model for art teaching quality evaluation during the epidemic. Based on the introduction of the BP neural network model and the problems of art teaching quality evaluation, the article focuses on the art teaching quality evaluation indicators and the BP neural network algorithm and process. In addition, the article also uses an empirical method to verify the effect of the BP network model training method, and obtains the expected effect. Finally, it discusses the problem of information processing in art teaching evaluation.
\end{abstract}

Keywords: Art teaching quality evaluation, BP neural network, COVID-19

\section{Introduction}

At the beginning of 2020, the normal teaching order was impacted by the epidemic of COVID-19, and the teaching quality was greatly affected. Teaching quality is one of the core contents in the education quality guarantee system, and it is also an important indicator reflecting the teaching level of teachers. Through the evaluation of teachers' teaching quality, the teaching management department can systematically, comprehensively and accurately understand the teaching level and quality of all kinds of curriculum teachers. Teaching quality evaluation can

*Corresponding author. Luo, Yuan, Wuhan Institute of Design and Sciences,WuHan 430205, HuBei, China. E-mail: 249190708@qq.com. also find out the experience and problems of teaching reform in time, so as to provide a reliable basis for decision-making. The evaluation can collect the objective reflection of the students on the teacher's teaching in the teaching process, and also provide feedback information for the teacher to improve the teaching. This plays a great role in promoting the improvement of teaching quality. Through evaluation, we can train a group of excellent teachers, especially for young teachers and teachers 'professional development. Evaluation is also conducive to the improvement of the overall quality of the teaching staff, and provides a fair, reliable, and scientific basis for the evaluation of teachers' positions [1].

Artificial neural network, also known as neural network, is a computer technology invented by 
American neurobiologist. Loch and mathematical logician W. Pitts in 1943 [2]. Artificial neural network ANN can simulate the neural activity of human brain, and use the mathematical model and algorithm system to get the relationship between the input sample information and the information through the adjustment of neuron weight and threshold value. It can also predict and analyze the relationship between other information. Therefore, it has good generalization ability. Artificial neural network has the following outstanding advantages: it can fully approach any complex nonlinear relationship; it has strong robustness and fault tolerance; it can quickly carry out a large number of operations; it has associative memory and learning functions; it can process quantitative and qualitative knowledge at the same time. These advantages of ANN can better adapt to the multi-factors, uncertainty and nonlinearity of teaching quality evaluation problems, it can overcome the shortcomings of other methods, quickly and objectively evaluate the teaching quality of teachers. In this paper, the neural network toolbox (NNT) of Matlab 7.1 is used to collect the evaluation samples of art college students, and to study the feasibility and effect of back propagation network on the evaluation of art teachers' teaching quality.

\section{The principles of establishing the evaluation index system of teachers' teaching quality}

To carry out teaching evaluation, we need to grasp the following principles:

- The principle of simplicity and scientificity. The evaluation index system should be appropriate in size and clearly reflect the quality of art teachers' teaching. If the evaluation index system is too large, too many and too fine, it will certainly attract the attention of the evaluator to the small problems. However, if the evaluation index system is too small, the index level is too small, and the index is too coarse, it cannot fully reflect and evaluate the overall level and teaching effect of teachers [4].

- The principle of fairness and rationality. That is to say, the evaluation index should be able to objectively, fairly and reasonably reflect whether the teaching process, teaching methods and methods of teachers are conducive to students' active learning and personalized learning.
- The Principle of operation convenience. The evaluation index system should be operable in practical application, with clear and reliable index meaning and easy data collection, which can be operated and applied by personnel who do not understand the establishment process of the index system.

- Practical principle. The evaluation system of teaching quality of art college teachers should embody the principle of attaching importance to practical teaching. We should pay attention to the cultivation of students' practical ability and establish an open practical teaching environment. All teaching activities should be based on the corresponding vocational field ability obtained by the students as the starting point and the end point, and give the students sufficient learning time and space to cultivate the students' ability and method of acquiring knowledge [3].

- The principle of overall consideration. The evaluation of teaching quality of teachers in art colleges is a systematic work, which is related to teachers, students, teaching facilities (equipment), teaching material construction and many other aspects. We should make a scientific overall plan. At the same time, the evaluation work should be combined with school orientation, training objectives and teaching management.

In order to meet the requirements of the current new situation, art education needs to constantly improve and improve its own development level through reform. The main carrier of art teachers to achieve this goal puts forward higher requirements for their teaching level. Therefore, it is necessary to take various measures to improve the teaching quality of teachers.

At present, many schools use the method of evaluating teachers by students. This method divides all the courses into several categories, such as theory courses, practice courses, experiment courses, etc., and sets up some evaluation indexes for each kind of courses. According to these indexes, the students give anonymous scores to the lecturers of the courses. The specific operation is that at the end of each semester, the academic affairs department or the University Evaluation Center will collect the students' scores, so as to strengthen the teaching management and improve the teaching quality of teachers. Although this way strengthens the school's management of teaching to a certain extent, and the evaluation results reflect the teachers' teaching level to a certain extent, 
there are some problems in this evaluation mechanism

- Teaching evaluation does not fully consider the differences of the evaluated teachers. Because of the difficulty of practical operation, the school did not set the evaluation index according to the difference of the nature of the art curriculum. It is impractical to adopt a unified evaluation method and standard for the different development stages of art discipline. Teachers in different disciplines and development stages should have different evaluation systems and standards. Even in the same discipline, teachers in the same development stage should have the difference between traditional curriculum teaching and new curriculum teaching [5].

- The main body of participating in the evaluation is too single, which is easy to cause one-sided results. According to the traditional teaching evaluation system, the main body of teaching evaluation is students, so the value orientation of students will directly affect the quality of evaluation results. To some extent, students' experience as the only subject of teaching evaluation results in one-sided teaching evaluation. Due to the ideological independence of college students, the evaluation of teachers is often based on their popularity, qualifications, professional titles, educational background, cognitive level, etc., which to some extent affects the scoring results. At the same time, students' interest in curriculum learning will also affect the evaluation results. They tend to pay more attention to whether teachers are funny, vivid and passionate in the classroom. This kind of guidance is more common, and the result often leads teachers to introduce some irrelevant content in lectures to meet the evaluation standards of students, thus ignoring the main content of the course.

- The evaluation method is lack of operability. At present, although the teaching quality evaluation of art teachers adopts the combination of normal and regular, qualitative and quantitative, supervision and students, but in the specific operation, there is no real assessment method with strong applicability and easy operation. For example, in the aspect of combining regular assessment with regular assessment, there is a lack of regular assessment. In the combination of qualitative and quantitative assessment, there is a lack of quantitative assessment. In the aspect of the combination of supervision and student assessment, there is a lack of supervision and assessment.

To sum up, the research and establishment of scientific evaluation standards and systems of teachers' teaching quality is not only the need of school system construction and standardized management, but also the direction of teachers' teaching behavior. It is imperative to establish a reasonable teaching evaluation index system.

The evaluation index system of art teachers' teaching quality is mainly composed of the following elements: the teaching concept, the implementation of the syllabus (plan), the teaching content, the teaching methods and means, the teaching cultivation and the basic skills of teaching. As shown in Table 1.

According to the characteristics of the two majors of urban and rural planning and human geography, and the adjustment ideas of the three major sections above, the curriculum system of urban and rural planning and human geography can be integrated. The overall idea for integration is: "Theoretical courses are compatible with skill courses, supplemented by direction courses".

In order to evaluate teachers' teaching quality and teaching effect objectively and accurately, 22 secondary evaluation indexes in the teaching quality evaluation index system need to be evaluated respectively, and the evaluation indexes are set as X1, X2, $\mathrm{X} 3, \mathrm{X} 4 \ldots \mathrm{X} 21, \mathrm{X} 22$, through a questionnaire survey of teachers and students in an art college. In the survey, the respondents are required to fill in and grade 22 evaluation indexes in the table. The value range of evaluation indexes is specified as $0-9$, and each person fills in a copy. After the summary, a teaching quality questionnaire as shown in Table 2 is established (only 21 samples and evaluation of some indexes are listed, others are omitted).

It can be seen from Table 2 that the 22 secondary indicators included in the teaching concept, syllabus (plan) implementation, teaching content, teaching methods and means, teaching accomplishment and basic teaching skills affect the teaching quality of art teachers to varying degrees. However, because the teaching quality evaluation system contains non-quantitative factors, and the input (22 evaluation indicators) and output (teaching effect) of the evaluation system are not necessarily simple linear relationships. Therefore, it is necessary to establish a reasonable and scientific mathematical model to find the mathematical relationship between 
Table 1

Evaluation Index System of Art Teachers' Teaching Quality

\begin{tabular}{|c|c|}
\hline First level index & Secondary index \\
\hline \multirow[t]{2}{*}{ Teaching philosophy } & Modern educational ideas and strong innovative ideas (X1) \\
\hline & Obvious awareness of teaching reform, forming their own teaching style (x2) \\
\hline \multirow{4}{*}{$\begin{array}{l}\text { Implementation of syllabus and } \\
\text { teaching plan }\end{array}$} & Education and subject objectives meet the requirements of syllabus (x3) \\
\hline & Complete the teaching tasks and contents specified in the syllabus (x4) \\
\hline & Ensure the continuity and systematization of learning content (x5) \\
\hline & Follow the teaching plan. No change without approval (x6) \\
\hline \multirow[t]{4}{*}{ Content of courses } & Teaching content should highlight the key points and difficulties (X7) \\
\hline & Clear knowledge level and strong logic (x8) \\
\hline & Timely introduction of new knowledge, theory and skills into classroom teaching (x9) \\
\hline & $\begin{array}{l}\text { Pay attention to the cultivation of students' practice and innovation ability, and strengthen the } \\
\text { relevant skills training of this course (X10) }\end{array}$ \\
\hline \multirow[t]{3}{*}{ Teaching methods and means } & $\begin{array}{l}\text { The teaching method should be selected according to the characteristics of the course, with } \\
\text { students as the center, learning and teaching (X11) }\end{array}$ \\
\hline & $\begin{array}{l}\text { The teaching method is flexible and diverse, which can stimulate students' participation } \\
\text { consciousness and innovative thinking (X12). }\end{array}$ \\
\hline & The modern teaching method is adopted reasonably, and the lecture image is vivid (x13) \\
\hline \multirow[t]{4}{*}{ Teaching accomplishment } & $\begin{array}{l}\text { Teachers influence students with a high sense of responsibility, a noble manner of speech and } \\
\text { behavior, and a rigorous attitude towards learning (x14) }\end{array}$ \\
\hline & $\begin{array}{l}\text { Teachers should answer students' questions patiently, teach students according to their } \\
\text { aptitude and guide them (x15) }\end{array}$ \\
\hline & $\begin{array}{l}\text { Teachers respect students' differences in teaching and arouse students' enthusiasm for } \\
\text { learning (x16) }\end{array}$ \\
\hline & Harmonious atmosphere between teachers and students in class (x17) \\
\hline \multirow[t]{4}{*}{ Basic teaching skills } & Proficient in Mandarin teaching. The language expression is accurate, fluent and clear. (X18) \\
\hline & The design of blackboard writing is reasonable, concise, neat and standardized (X19) \\
\hline & $\begin{array}{l}\text { The teaching style should be natural, dignified, generous and friendly, and the clothes should } \\
\text { be neat (X20) }\end{array}$ \\
\hline & $\begin{array}{l}\text { Scientific and reasonable allocation of teaching time and high efficiency of classroom } \\
\text { teaching (X21) To attend and leave class on time, not late, leave early, not delay (X22) }\end{array}$ \\
\hline
\end{tabular}

Table 2

Questionnaire on teaching quality of art teachers

\begin{tabular}{|c|c|c|c|c|c|c|c|c|}
\hline \multirow{2}{*}{$\begin{array}{l}\text { Serial } \\
\text { number }\end{array}$} & \multicolumn{7}{|c|}{ Evaluation index (secondary index) } & \multirow{2}{*}{$\begin{array}{r}\text { Evaluation } \\
\text { objectives }\end{array}$} \\
\hline & $\overline{\mathrm{X} 1}$ & $\mathrm{X} 2$ & $\mathrm{X} 3$ & $\mathrm{X} 4$ & $\mathrm{X} 5 \ldots \mathrm{X} 20$ & $\mathrm{X} 21$ & $\mathrm{X} 22$ & \\
\hline 1 & 6.5 & 5 & 7 & 4.5 & $\ldots \ldots$ & 6 & 7 & 7.75 \\
\hline 2 & 3 & 9 & 4 & 6 & $\ldots \ldots$ & 7.5 & 6 & 6.5 \\
\hline 3 & 6 & 6.5 & 8 & 4 & $\ldots \ldots$ & 7 & 6.5 & 6.5 \\
\hline 4 & 7 & 6.5 & 8 & 6 & $\ldots \ldots$ & 6 & 7 & 7.25 \\
\hline 5 & 8.5 & 4 & 9 & 5.5 & $\ldots \ldots$ & 8.5 & 7 & 8.5 \\
\hline 6 & 6 & 7.5 & 6.5 & 7.5 & $\cdots \cdots$ & 7 & 7.5 & 7.25 \\
\hline 7 & 7.5 & 4 & 8 & 6.5 & $\ldots \ldots$ & 6 & 7 & 8 \\
\hline 8 & 6.5 & 5.5 & 6 & 9 & $\ldots \ldots$ & 7 & 6 & 6.25 \\
\hline 9 & 7 & 3 & 6 & 5 & $\ldots \ldots$ & 5.5 & 6.5 & 6.75 \\
\hline 10 & 8 & 3 & 9 & 5.5 & $\ldots \ldots$ & 7 & 7 & 7.5 \\
\hline 11 & 7 & 6 & 8 & 4 & $\ldots \ldots$ & 6.5 & 7 & 6.75 \\
\hline 12 & 6 & 8 & 7 & 7.5 & $\ldots \ldots$ & 6.5 & 7 & 7.5 \\
\hline 13 & 6.5 & 6.5 & 6 & 5 & $\ldots \ldots$ & 5.5 & 6 & 6.75 \\
\hline 14 & 7.5 & 8.5 & 5 & 7 & $\ldots \ldots$ & 8.5 & 7.5 & 6.75 \\
\hline 15 & 6 & 9 & 5.5 & 6.5 & $\ldots \ldots$ & 6.5 & 5.5 & 6 \\
\hline 16 & 6 & 9 & 5 & 7 & $\ldots \ldots$ & 8 & 6.5 & 6.5 \\
\hline 17 & 7 & 5.5 & 8 & 5.5 & $\ldots \ldots$ & 7 & 7.5 & 7.5 \\
\hline 18 & 4 & 7.5 & 3.5 & 5.5 & $\ldots \ldots$ & 4.5 & 6 & 6.25 \\
\hline 19 & 4 & 8 & 6 & 5.5 & $\ldots \ldots$ & 6.5 & 6 & 6.5 \\
\hline 20 & 5.5 & 4 & 5 & 3 & $\ldots \ldots$ & 4 & 7 & 6.75 \\
\hline 21 & 9 & 6.5 & 8 & 6 & $\ldots \ldots$ & 6.5 & 8 & 8 \\
\hline
\end{tabular}


the input and output of the evaluation system, which has important practical significance for the objective and fair evaluation of the teaching quality of art teachers.

\section{Evaluation model of teachers' teaching quality based on neural network}

\subsection{Introduction to BP neural network}

BP neural network was proposed by Rumelhart et al. Based on the research achievements of modern neuroscience [6], neural network theory attempts to simulate the way the human nervous system processes, memorizes, and processes information in order to design an information processing system with a human brain feed-forward network style. According to statistics, in the practical application of artificial neural networks, nearly 9 neural network applications are based on the BP algorithm and its variants. The BP neural network embodies the most essential part of the artificial neural network and has a good ability to approximate nonlinear mapping., And it is very suitable for solving problems with few rules, multiple constraints or incomplete data, such as complex classification and pattern recognition. Specifically, the neural network can automatically learn the previous experience from the provided data samples, without the need for cumbersome query and expression process, and can automatically approximate the functions that describe the regularity of the sample data, regardless of the form of these functions. For those situations where the influencing factors are more complex and the degree of nonlinearity is higher, the advantage of neural networks is more obvious. It can be widely used in various data such as prediction, classification pattern recognition and process control.

\subsection{Neural network model and learning algorithm for teachers' teaching quality evaluation}

BP neural network (Back Propagation NN) is a unidirectional multi-layer forward neural network. The network can be divided into input layer, intermediate layer and output layer, in which the input and output are only one layer, the intermediate layer can have one or more layers. There is no connection between network nodes on the same layer. Each network node represents a neuron. The input signal is input from

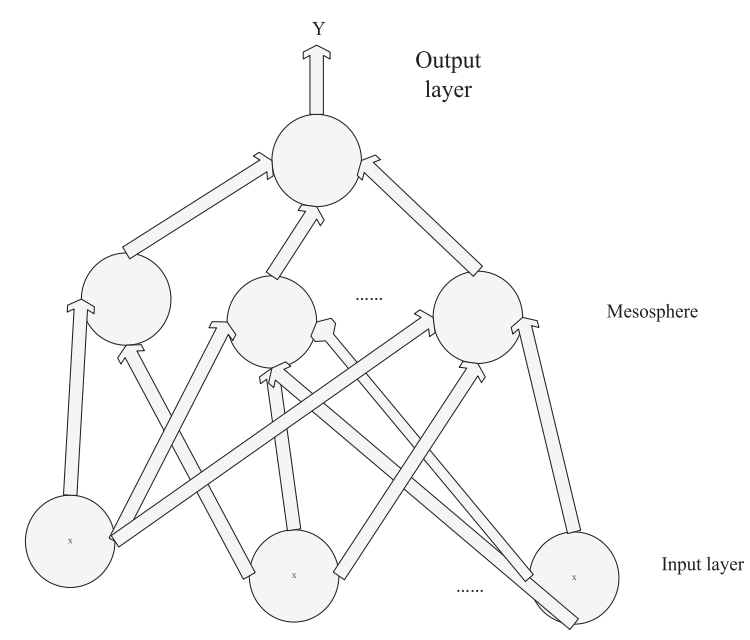

Fig. 1. Three-layer neural network structure diagram of BP.

the input layer node, then passes through the middle hidden layer node, and then is transmitted to the output node. The output of each layer of nodes only affects the output of the next layer of nodes. Kolmogorov's theorem shows that a 3-layer BP neural network containing only input layers, single hidden layers and output layers can achieve arbitrary continuous mapping [7]. In 1989, Robert Hecht Nielson proved that any continuous function in a closed interval can be approximated by a BP network with an implicit layer, and a 3-layer BP network can complete any $\mathrm{N}$-dimensional to $\mathrm{M}$-dimensional mapping [8]. For the determination of the number of hidden neuron nodes, the cell characteristic transfer function usually uses a Sigmoid-type transformation function, and the cell characteristics of the output layer nodes can be expressed linearly [9].

This article uses BP neural network to identify the teaching quality evaluation system of art teachers. Here, the 22 secondary evaluation indicators are used as the input of the neural network system, and the teacher's classroom teaching effect is used as the output of the system. Its structure is shown in Fig. 1.

Let the input layer of the BP network $\mathrm{X}=\{\mathrm{x}(1) \ldots x(\mathrm{n})\}$, Among them, $\mathrm{X}(1) \sim \mathrm{X}(\mathrm{n})$ are various evaluation indexes of the teacher's teaching quality evaluation system. In this study, the value of $\mathrm{n}$ is 22 , that is $n=22$.

The hidden layer of the network is:

$$
n e t_{i}=\sum v_{i j} x_{1} o_{i}=a\left(n e t_{i}\right)
$$

where $v_{i j}$ is the weighting coefficient and $\mathrm{a}(\mathrm{x})$ is the system's excitation function or transfer function, tak- 
ing the Sigmoid function, namely:

$$
a(x)=\frac{1-e^{-x}}{1+e^{+x}}
$$

The output layer of the network is: $\hat{y}=\sum_{i} w_{i} o_{i}$

Among them, $\hat{y}$ is the output variable of the neural network system, $\left\{w_{i}\right\}$ is the weighting factor.

Let the criterion function be:

$$
E=\frac{[y-\hat{y}]}{2}=\frac{e^{2}}{2}
$$

Using BP algorithm can minimize the performance index, In order to ensure the overall stability of the system, the actual output y of the identified object (teaching quality evaluation system) is used as a feedback signal and compared with the output $\hat{y}$ of the neural network identifier. And $\mathrm{E}<\varepsilon$ ( $\varepsilon$ is a very small number). If it does not meet the requirements, it is necessary to constantly adjust the number of weights to meet the expected requirements.

For the basic BP, the algorithm steps can be further improved, and then the improved BP learning algorithm steps can be followed:

- Firstly, the network model structure, learning parameters and network connection weights are initialized.

- Then input the input vector $\mathrm{X}$ and the expected output vector D.

- The output vectors of each layer of the model are calculated.

- Use the following formula to calculate the cumulative error.

$$
E=\frac{1}{2} \sum_{P=1}^{P} E p=\frac{1}{2}\left(d_{p}-y_{p}\right)^{2}
$$

- The error signals of each layer of the model are calculated.

- When all samples are finished, proceed to the next step, otherwise return (2)

- Adjust the network connection weight of each layer.

$$
\begin{gathered}
w_{j}=w_{j}+\eta \sum_{p=1}^{p} \delta_{j} \mu_{j}+\alpha \eta \sum_{p=1}^{p} \delta_{j} \mu_{j} \\
v_{j}=v_{i j}+\eta \sum_{p=1}^{p} \delta_{i j} \mu_{j}+\alpha \eta \sum_{p=1}^{p} \delta_{i j} x
\end{gathered}
$$

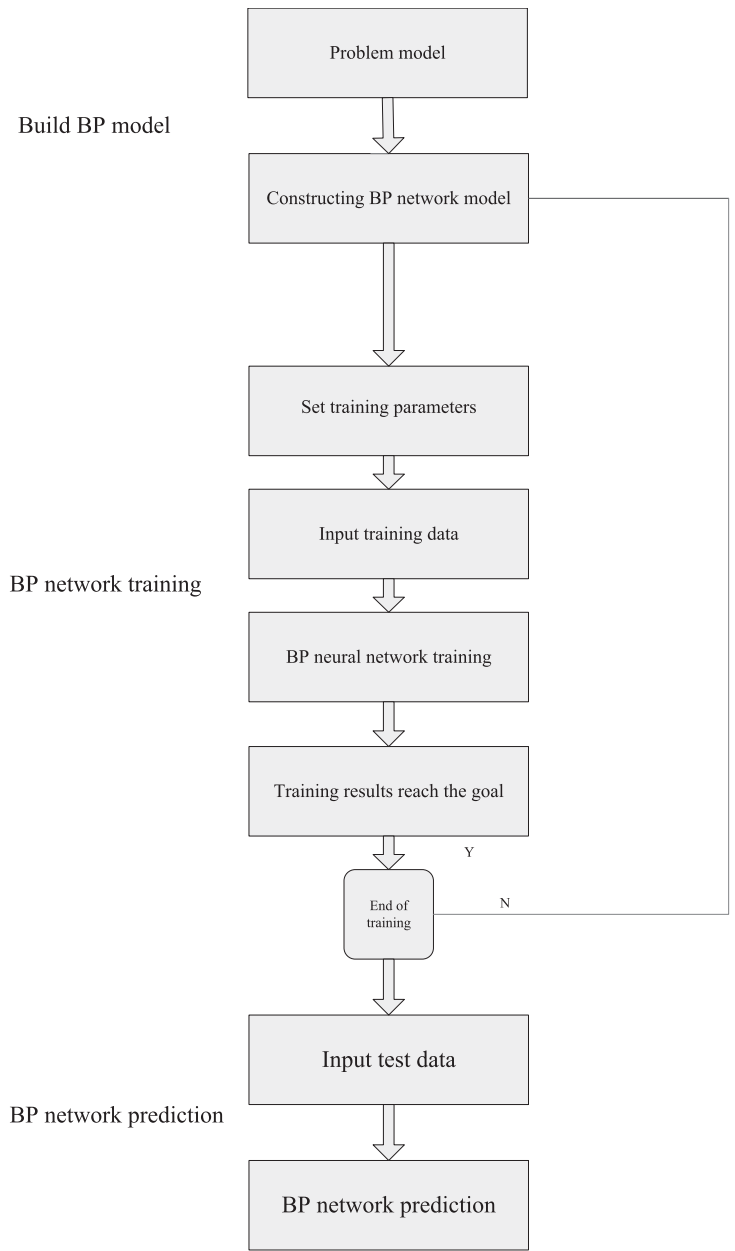

Fig. 2. Flow chart of the BP neural network model.

- Judge whether the learning is over. If every $\mathrm{P}$ and $\mathrm{K}$ is satisfied If each $\mathrm{P}$ and $\mathrm{K}$ satisfies $\mid d_{t}^{p}-$ $y_{t}^{p} \mid \varepsilon$, or reaches the maximum of the set training times, then the learning is finished, otherwise continue to the next step.

\section{Experiment results and analysis}

First, the BP network can be created by the function newff, which establishes the network object and initializes the network weight and threshold. Network training is realized by function train, and network simulation is realized by function sim. The above process can be used to model and solve practical problems. Figure 2 is the realization process of $\mathrm{BP}$ network modeling in MATLAB. 


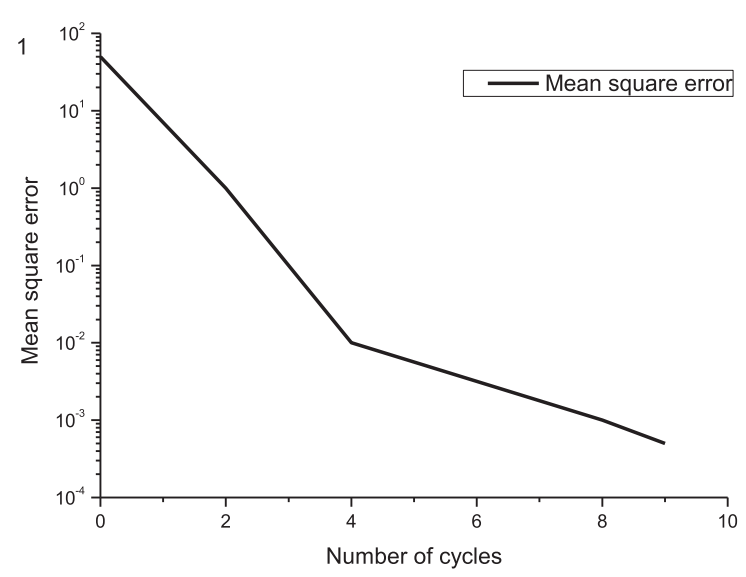

Fig. 3. Training process of BP neural network system.

The three-layer BP neural network is used to identify the above-mentioned teacher teaching quality evaluation system. The number of nodes in the input layer, the hidden layer and the output layer are $22 \times 44 \times 1$ respectively. The sigmoid learning rate $\eta=0.9$ is used as the activation function. The back propagation (BP) algorithm is used as the learning algorithm. The data in Table 2 is used as the training sample of the neural network identification model, the target error is 0.001. MATLAB software is used for simulation experiment to get the training process curve as shown in Fig. 2. After the training meets the requirements, the identification value shown in Table 3 can be obtained. It can be seen from Table 3 that the original data is very close to the identification value of the neural network system, that is to say, the model can determine the teaching quality and effect of teachers according to each evaluation index more accurately [10].

As for the information processing methods of education evaluation, each school is different, and the network teaching platform used has no unified reference standard in function, content, development technology, management means, etc. As far as the current situation is concerned, there is basically no platform that can provide more abundant means of education evaluation in the network teaching platform. On the one hand, due to the lack of participation of educational experts in the design and development of the platform, the design of educational information processing module is not considered in the framework design of the system. On the other hand, there are many means of educational evaluation, and the methods of educational information processing are different. The difficulty of development and the long cycle affect the enthusiasm of developers. The development of middleware technology provides a reusable development means for the educational information processing and educational evaluation activities under the network teaching environment. Middleware is a kind of independent system software or service program, with which distributed application software shares resources, manages computing resources and network communication among different technologies. Middleware, as a special layer between system software and application, abstracts the typical application mode, so that application software manufacturers can put more ideas in business logic and develop based on the standard form. In order to complete application integration and business process integration, it is necessary to solve the problem of data and database integration. Before integration, the data must be identified and catalogued, and the metadata model must be determined [10].

Combined with educational evaluation methods and educational information processing methods, a large number of educational information (data) complex processing is encapsulated with middleware technology to form educational information processing software package (i.e. educational information processing middleware). The compiler of educational software is based on the functions provided by the middleware, the data communication between software and middleware is completed by combining the data interface or data model of middleware.

Table 3

Comparison and analysis of identification values of original data and neural network

\begin{tabular}{lcccccccc}
\hline $\begin{array}{l}\text { Serial } \\
\text { number }\end{array}$ & $\begin{array}{c}\text { Evaluation } \\
\text { objectives }\end{array}$ & $\begin{array}{c}\text { Identifica- } \\
\text { tion value }\end{array}$ & $\begin{array}{c}\text { Serial } \\
\text { number }\end{array}$ & $\begin{array}{c}\text { Evaluation } \\
\text { objectives }\end{array}$ & $\begin{array}{c}\text { Identifica- } \\
\text { tion value }\end{array}$ & $\begin{array}{c}\text { Serial } \\
\text { number }\end{array}$ & $\begin{array}{c}\text { Evaluation } \\
\text { objectives }\end{array}$ & $\begin{array}{c}\text { Identifica- } \\
\text { tion value }\end{array}$ \\
\hline 1 & 7.35 & 7.7487 & 8 & 6.25 & 6.2532 & 15 & 6 & 5.9594 \\
2 & 6.4 & 6.4895 & 9 & 6.75 & 6.7587 & 16 & 6.5 & 6.4595 \\
3 & 6.5 & 6.4891 & 10 & 7.5 & 7.4596 & 17 & 7.5 & 7.4591 \\
4 & 7.75 & 7.2606 & 11 & 6.75 & 6.7504 & 18 & 6.25 & 6.2542 \\
5 & 8.3 & 8.4928 & 12 & 7.5 & 7.4592 & 19 & 6.5 & 6.5512 \\
6 & 7.26 & 7.2510 & 13 & 6.75 & 6.7514 & 20 & 6.75 & 6.7508 \\
7 & 8 & 7.9989 & 14 & 6.75 & 6.7597 & 21 & 8 & 7.9584 \\
\hline
\end{tabular}


If we analyze the structure of educational information processing middleware, we should have two basic modules:

- Data interface module. Data structure module consists of standard information source object interface, external specification information, metadata inspection and standard information feedback interface

- Information processing object module. The data are calculated and processed according to the selected evaluation method. The most common way to achieve data communication is to use parameter transfer to transfer data to middleware. However, for the transfer of a large number of data, this method is more cumbersome and error prone. Using XML technology to transfer data can solve these problems thoroughly. Specifically, according to the data interface or data model of the middleware (written in XML), the education software combines its own data storage structure and uses SOA p to transfer the XML file conforming to the specification to the middleware. The middleware obtains all the data needed from the XML file provided by the education software and processes it, and feeds back the processing results to the education software. Finally, the information processing of education evaluation is realized.

\section{Conclusions}

At the beginning of 2020, the normal teaching order was impacted by the epidemic of COVID19 , and the teaching quality was greatly affected. The evaluation of teachers' teaching quality has experienced the traditional statistical analysis and evaluation model, fuzzy evaluation method, grey decision-making method, analytic hierarchy process and so on. The above evaluation methods have played a certain role in the evaluation of teachers' teaching quality in a specific time and scope. However, the evaluation of teachers' teaching is a rather complex problem, so up to now, there is no generally accepted evaluation index system is the best, and all of the above methods have their limitations. In recent years, BP neural network has achieved good results in pattern recognition, recognition filtering, automatic control and prediction. It can process any complex data without knowing the cause of data generation, and can approach any complex nonlinear relationship with any precision. Teachers' teaching evaluation is of great significance to improve teaching quality, teachers' quality and students' learning effect. The evaluation system of College Teachers' teaching quality is a high-dimensional non-linear relationship, and the evaluation method of teachers' teaching quality based on BP neural network is relatively more reasonable, scientific and feasible in the processing of weights and data.

This paper studies some methods of teachers' teaching evaluation by predecessors, analyzes the advantages and disadvantages of the methods they adopt, and puts forward a teacher's teaching evaluation model based on BP neural network. This paper uses MATLAB to build BP neural network for training, simulation and testing. The evaluation results are very close to the expert evaluation results. It is a feasible and reasonable teaching quality evaluation model. Mainly in two aspects.

The Based on the analysis of the structure and principle of neural network, especially BP model, this paper applies it to the evaluation of teaching quality index system of art college teachers. It is proved that the error between the output identification value and the real value of the mathematical model established by BP neural network is very small, so that the teaching quality and teaching effect of higher vocational teachers can be evaluated scientifically and accurately.

Neural network has the characteristics of "similar shape input, similar shape output". The evaluation accuracy and scientificity of this method not only depend on the number of training samples, but also on the quality of training samples. Practice has proved that the more training samples, the more accurate the mathematical model can describe the quality of teaching effect according to each evaluation index. Because of its high self-organization, self-adaptive and self-learning ability, it can weaken the influence of human factors in the determination of index weight, so it is superior to other evaluation methods.

\section{References}

[1] J. Daogen and Z. Bin, RBF Neural Network Teachers 'teaching Quality Evaluation in Vocational Colleges, Journal of Ningbo City Vocational and Technical College 2017(12), 36.

[2] Z. Zhenkun, Evaluation Model of Scientific Research Ability of University Teachers Based on Bp Neural Network, Digital Technology and Application 2014(01), 62-64. 
[3] S. Duanchao, W.C. Hua and W. Xingzi, Evaluation model of military school classroom teaching quality based on BP neural network, Continuing Education 2017(12), 49-51.

[4] S. Li, S. Zhimei, L. Yi and X. Jiajing, Bp Neu-ral Network Model for Teaching Quality Evaluation, Information Construction 2015(04), 83-85.

[5] C. Hongjun and Y. Haitao, The Application of Rbf Neural Network in the Quality Evaluation System of Teachers in Higher Vocational Colleges, Science and Education Guide (mid Ten Issue) 2017(02), 82-83.

[6] Y. Jian, P. He and L. Haiyan, Research on the Evaluation of Teaching Quality Based on Grey Neural Network, Heilongjiang Animal Husbandry and Veterinary (2014), 42-45.
[7] S. Li and S. Zhimei, Bp Neural Network Model for Teaching Quality Evaluation, Software 2015(03), 25-27.

[8] L. Yishi, L. Xujiajing and F. Wenjie, Research on Evaluation of Teaching Quality Based on Bp Neural Network, Journal of Hubei University of Economics: Humanities and Social Sciences 2015(12), 188.

[9] Z. Li, Evaluation of Teaching Quality of University Teachers Based on Structural Equation Model, Statistics and Decision Making (2014), 63-65.

[10] R. Yanhui, Teaching Evaluation Research Based on Quantum Bp Neural Network, Information Technology 2014(05), 129-131. 